would be possible to alter the character of a central research organization. At present its greatest danger is that of becoming a static body of researchers cut off from the real needs of industry. It should be able to become a common research centre with a continuous flow of men through it, providing a laboratory where any man with a good idea could come to work it out, and a source of men going back into industry with a wider knowledge of all its problems. It is only under such conditions that really fundamental advances can be made.

\section{THE EYE IN INDUSTRY}

$\mathrm{C}$ URRENT interest in the health of industrial workers and in the maintenance of a high level of output made the conference on the "Eye in Industry", held under the auspices of the London Branch of the Institute of Physics on June 20, very opportune. During the first half of the proceedings six papers were given on different aspects of the subject, followed, after tea, by a lively discussion, in which many of the audience took part. The success of the meeting was enhanced by the kindly hospitality enjoyed at the South-West Essex Technical College, where the conference was held.

In the opening paper, Dr. W. D. Wright gave three reasons for a discussion on the eye in industry as opposed to the eye in other spheres of human activity. There is in the first place the special nature of many of the tasks that have to be undertaken and that are peculiar to industry, tasks, moreover, that have to be repeated and continued for many hours at a stretch. Secondly, there is the question of responsibility, either on the part of the employer or possibly of some Government department, for the health of the workers. In the home, the individual should, so far as his means permit, make his own arrangements for good lighting and avoidance of eyestrain, but in the factory the onus rests on the employer. Any discussion should therefore aim at stirring the interest and the conscience of the employer, providing him with the data that he may properly demand and informing him of the facilities already available for the adequate solution of visual problems. There is thirdly the question of output and efficiency, matters closely related to good seeing.

Hence, although the eye responds in the factory in much the same way as it responds elsewhere, yet there are excellent reasons for paying special attention to its performance under industrial conditions. The importance of the eye, as distinct from the other sense organs, lies, of course, in the fact that a very large fraction of our knowledge of the external world is derived visually. Nearly all the information which we have of our immediate surroundings and of the events taking place in the vicinity is obtained from the very variegated pattern of light, shade and colour which is focused by the lens system of the eye on to the light-sensitive retina. Shape, size, texture, distance and movement of an object, are all observed and recorded because of the existence of contrasts between the object and its background and between different markings on its surface, as in the grain in a piece of wood, so that good seeing demands good contrast perception. Attention has to be paid to the image-forming part of the visual system, as this may be defective and require correction with spectacles, and also to the performance of the light-sensitive mosaic on the retina, which can detect small contrasts and resolve finer detail when the level of illumination is raised. Eyestrain occurs when the muscles controlling the convergence of the two eyes on to the object under examination and those governing the focusing of the lens system have to operate under conditions of poor visibility and distracting lighting. It is the job of the employer to provide conditions that achieve the best possible compromise between the requirements of his technical processes and the maintenance of maximum visual efficiency.

Mr. E. W. H. Selwyn illustrated this compromise by reference to the peculiar problems that arise in the photographic industry in connexion with the illumination of dark rooms. Sufficient light has to be provided to conduct the various photographic processes, but not so much as to fog the emulsion. In choosing the colour of the light to be used, a balance has to be struck between the parts of the spectrum to which the photographic emulsion is least sensitive and the eye most sensitive, taking into account the changing spectral sensitivity of the retina in dim illumination. It follows that the most efficient colour of the illumination will vary with the type of emulsion : orange for ordinary emulsions, red for the orthochromatic type, and green for the panchromatic and infra-red forms. In all cases the level of illumination is low, leading to poor visual acuity and contrast perception. As a consequence, objects such as dark room clocks must be large, and white markings should be provided to assist in getting about the dark room-aids reminiscent of the black-out.

Another interesting aspect of the problem is concerned with the time required to become adapted to the dark room illumination. In rooms illuminated by red light, vision, even when fully adapted, is mediated largely through the cone mechanism in the retina and the cones acquire their maximum sensitivity after only a few minutes. In the rooms illuminated by green light, on the other hand, the rods will operate, and as these take at least thirty minutes to acquire their maximum sensitivity, there is a marked difference in the adaptation times for the two forms of lighting. Mr. Selwyn also reported his experience that when working in a dark room he found that he required the aid of negative lenses with a power of -2 dioptres in order to focus distant objects clearly. This he attributed to the spherical aberration in the lens system of the eye, since at low intensities the iris is expanded and the marginal zones of the system come into action. There was some difference of opinion on this matter during the discussion, both as to magnitude of the effect and its cause. It would appear that some observers have not been conscious of the need for negative lenses; indeed, one speaker maintained that positive lenses were required, yet it is not a matter that should be lightly dismissed without further investigation.

The part played by light in aiding the performance of the eye was dealt with by Mr. W. R. Stevens. He stated the basic principles of good lighting, including adequate illumination, reasonable uniformity, freedom from glare and the provision of the proper contrast between the object and its surround. He urged the greater use of colour, both as a means of improving contrasts and in brightening our workshops ; in Great Britain we tend to be conservative in our devotion to greys and other dull colours for the decoration of machinery, with the notable exception 
of the gaily coloured agricultural machines. An important advance in the last few years has been the introduction of the fluorescent tube as a light source; its extended area and low brightness result in a reduction of hard shadows and the absence of glare, while through the choice of the fluorescent material, the colour can be controlled very successfully. A good approximation to daylight can be obtained, and, through the employment of daylight fluorescent lamps, the illuminating engineer can mix artificial light with daylight without introducing the disturbing rsthetic appearance noticeable when ordinary tungsten lamps are used in a room which is simultaneously being illuminated by daylight.

Questions were asked about the extent to which the design of lighting installations should attempt to simulate daylight, both in its colour and distribution ; the evidence goes to show that generally we prefer the lighting to which we have been accustomed, so that any tendency towards one particular form of installation has no justification from experience. The design of windows and daylighting is largely an architectural problem, and for illuminating engineers to arrange their lighting fixtures to give an imitation of window lighting would impose an unnecessary, artificial restriction on the freedom they otherwise possess.

Mr. G. H. Giles, who spoke from the point of view of the optician, claimed that the optician is in a position to act as a clearing station for the specialist -the physicist, the illuminating engineer, the medical practitioner. There is a very obvious need for close attention to refractive errors among the workers in industry, since statistics, many from the United States, show that the percentage of workers with visual defects is very high. Correction of the defects with spectacles leads to roughly 20 or 30 per cent increased production, with a corresponding decrease in the discomfort and fatigue of the worker. Naturally, there is a greater tolerance for defects in one type of work than in another, but there are occupations where visual aids are desirable, even though the vision of the worker is normal. Thus, where prolonged close work is involved, it has been found that much of the strain can be removed if the worker wears a pair of glasses which combine a lens and prism for each eye. In this way most of the need for excessive focusing and excessive convergence of the two eyes can be avoided, with a consequent lessening of the muscular effort; Weston and Adams have shown that great benefits have resulted from the use of such aids, leading to a marked reduction in fatigue and eyestrain, and a significant increase in output. During the discussion, the value of spectacles of this type was especially emphasized in the case of prolonged near work and it was considered that they could be employed on a far wider scale than is the case at present.

Tests for eye defects other than refractive errors, such as colour blindness and defective night vision, may also be needed. Recently, a number of workers at a factory claimed to have poor night vision, but when tests proved them to be normal, it transpired that they had hoped in this way to avoid fire-watching duties! Opticians also deal with protective glasses against damage from different radiations and from other hazards such as flying chips and molten substances. Finally, Mr. Giles referred to a scheme inaugurated by the Joint Council of Qualified Opticians for testing the vision of factory workers, whereby a rota of opticians is made available for the purpose. A valuable service was being performed in this way before the War, but during the War the scheme has proved even more useful and has been officially adopted for Royal Ordnance Factories.

The routine eye examination carried out by opticians under the scheme of the Joint Council of Qualified Opticians was described in some detail by Mr. R. A. Rider. As the testing of each patient may occupy at least thirty minutes, the time required to deal with a works in which, say, 20,000 persons are employed is very great. The tests may therefore have to be directed in the first place to those who show symptoms of ocular defect.

In the final paper Dr. H. Lowery broached a rather different aspect of the subject when he referred to the part played by the eye during training for such activities as carpentry, metal work and other technical handicrafts. This is very much a question of securing proper co-ordination between hand and eye and it is important, especially at the present time, to know why and how training improves the visual processes. Before the War of 1914-18 it was customary in schools to give special classes for what was called "eye training", but since then the method has been discarded. It is undoubtedly in part a psychological problem, as are, in fact, all visual problems, and training undoubtedly induces alertness in making particular types of observation. In the discussion, for example, reference was made to the very high accuracy to which a trained workman could judge angles and other dimensions of an object. Another point was made that, in problems of discrimination and visual estimation, the boundary line between physiology and psychology is rather vague, so that the possibility that training may modify the response of the eye as well as the reaction in the brain ought not to be overlooked.

There is obviously a great deal still to be learnt about how the eye works and how to apply the information that is available. The problem is a vast and intricate one and the conference served to bring different interests together to form a pool of knowedge, knowledge that has somehow to be passed on to the whole industrial community.

\section{CANCER RESEARCH IN GREAT BRITAIN}

$T$

THE eighteenth annual report of the Grand Council of the British Empire Cancer Campaign (11 Grosvenor Crescent, London) was issued in February. At the meeting at which the report was presented, it was stated that more cancer research had been carried on during the War than had been anticipated in 1939. The summary refers with justifiable pride to "the lead in cancer research which Britain is still giving to tha whole world". On account of this, appeals for financial assistance for the Cam. paign which had been discontinued at the beginning of the War will be made again.

The report itself has its familiar form, and shows that a considerable amount of work has been carried out in Great Britain, though there is little research to report from the Dominions. During the year which ended last summer the campaign expended almost $\mathfrak{1 4 5 , 0 0 0}$ in supporting research workers and institutions.

Advances in our knowledge of cancer have been made in many countries. Important contributions 